\title{
REDUCTION OF WAVE OVERTOPPING ON A SMOOTH DIKE BY MEANS OF A PARAPET
}

\author{
Koen Van Doorslaer ${ }^{1}$ and Julien De Rouck ${ }^{1}$
}

\begin{abstract}
A return wall or parapet is a very efficient construction built to reduce wave overtopping over sea structures. One of its main advantages is that this relative small construction can be built in a dike without increasing the crest height yet creating a major reduction in wave overtopping. In this paper only non-breaking waves attacking smooth dikes are investigated. A normal smooth dike, a smooth dike with vertical wall and a smooth dike with parapet have been tested. The results lead to reduction factors for a vertical wall or a parapet that can be introduced in the van der Meer formulas for wave overtopping over smooth dikes. The optimal geometry of the parapet has been subject of the research as well.
\end{abstract}

Keywords: wave overtopping, reduction, reduction factors, smooth dike, vertical wall, parapet

\section{INTRODUCTION}

The $67 \mathrm{~km}$ long shoreline of Belgium is with 450.000 inhabitants a highly populated area. A similar trend exists worldwide: coastal zones belong to the areas with highest population densities. Apart from highly populated, coastal zones are also of major economical (harbors), ecological and touristic value. It is clear that coastal zones need to be protected against human impact (e.g. pollution), but also against nature (e.g. storms). Both soft (dunes, beaches) and hard (dikes, breakwaters, ...) safety measures can be foreseen to protect the coastal area against wave impact and flooding of the hinterland.

In Belgium, the typical geometry of the main part of the coastline is a combination of soft and hard measures: a sandy beach under a very mild slope (1/100 to $1 / 50)$ followed by a smooth dike and a horizontal promenade, see Figure 1. During storms with return period even below 10 years, the water level can reach the smooth dike at some locations, and create too much wave overtopping

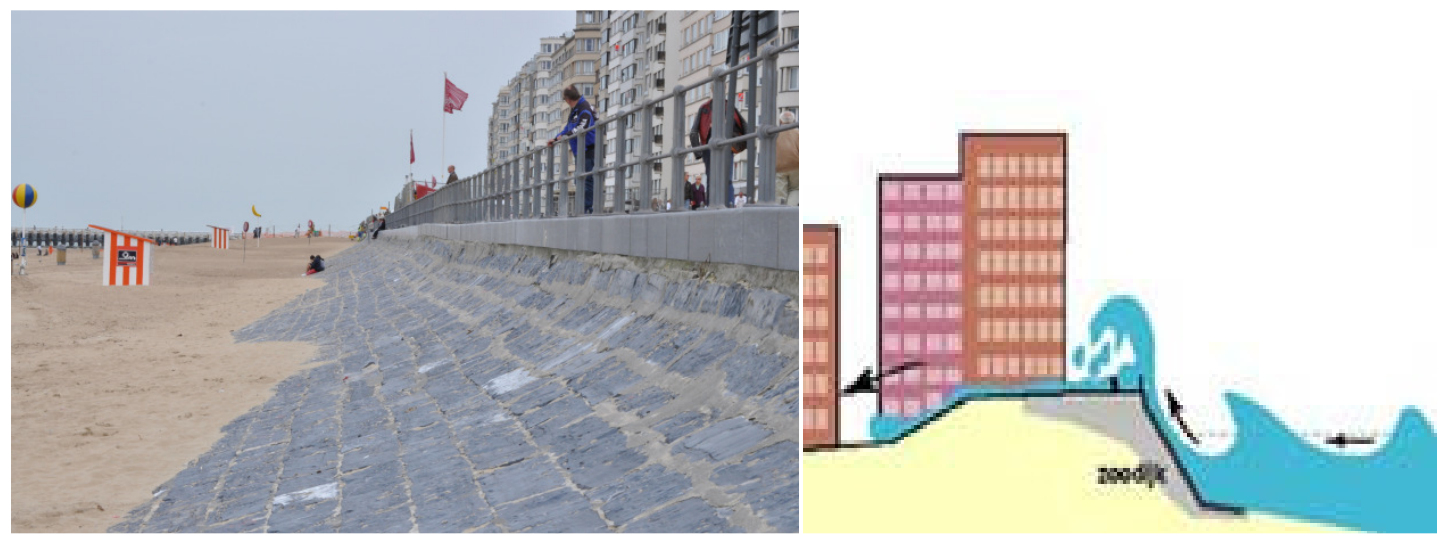

Figure 1. Typical beach profile in Belgium (left) causing danger during storms (right)

According to the Belgian Integrated Coastal Safety Plan (ICSP), this coastline has to remain safe under a storm with a return period of 1000 years and mean overtopping discharges has to be kept below $11 / \mathrm{s} / \mathrm{m}$. If this storm would have occurred before any of the suggestions in the ICSP were executed, one third of the coastal zone would have been insufficiently protected. Dike instability, breaches and flooding would have occurred, creating an economical disaster and the loss of many lives.

Emergency solutions were carried out, and long term solutions have been researched. All those solutions had to take the spatial restrictions along the Belgian coastline into account: beach nourishment over the full length of the unsafe zones is expensive, not permanent and not possible at every location (e.g. near harbors). Increasing the crest level or the crest width is also not possible: building a high storm wall for example is not wanted due to the visual implications. Alternative solutions without modifying the crest height were researched in the 2D wave flume of Ghent University, and are presented in this paper.

\footnotetext{
${ }^{1}$ Dept. of Civil Engineering, Ghent University, Technologiepark 904, 9052 Zwijnaarde, Belgium Koen.VanDoorslaer@ugent.be - julien.DeRouck@UGent.Be
} 
WAVE OVERTOPPING REDUCTION WITH THE SAME CREST HEIGHT

In the past, vertical (crown)walls have been built into the smooth dike along the Belgian coast as shown in Figure 2. This simple measure already reduces wave overtopping.

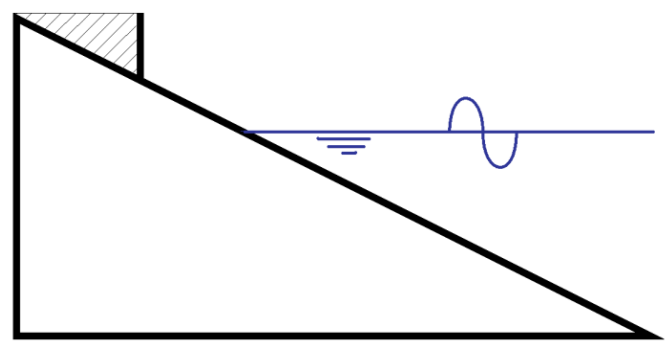

Figure 2. Vertical wall on a smooth dike

In order to reduce the overtopping even more, with only minor adjustments to the existing construction, a "nose" has been added to the vertical part of the (crown)wall. By doing this a so called parapet is built. The open space can be filled up, meanwhile creating a wider crest (right on Figure 3).
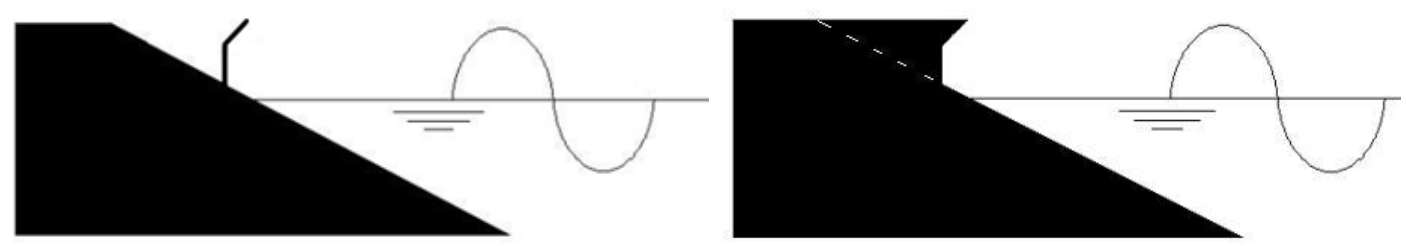

Figure 3. Smooth dike with parapet
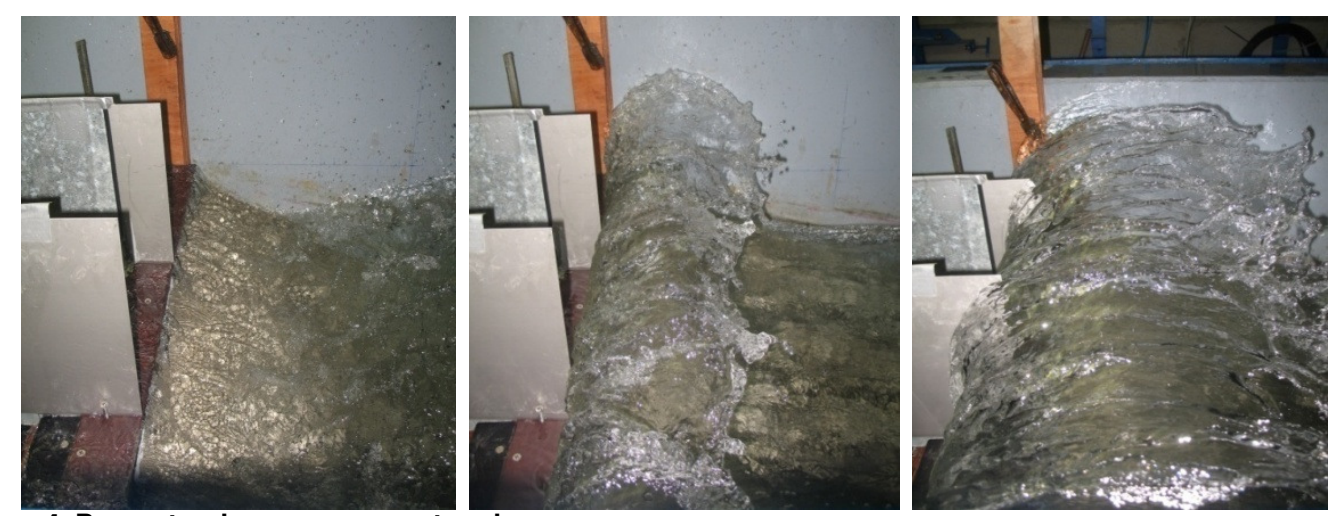

Figure 4. Parapet reduces wave overtopping

With a parapet waves are not only projected upward, but also back to the open sea. This can be seen on pictures taken during the scale model testing (Figure 4). The principle of a parapet has already been introduced to reduce wave overtopping at vertical seawalls (Goda 1985, Franco 1994), and a few tests have been executed by (Den Heijer 1998) with a fixed parapet at a sloping seawall with berm. In the previous papers, a non-variable reduction factor $\gamma_{p}=0.7$ has been proposed.

In the present paper, the influence of the geometrical variations of the height and angle of this nose is discussed, in order to find the optimal geometry of the parapet located on the smooth dike (without berm). Smoothly curved parapets have not been investigated, since the modification of the existing vertical (crown)wall at the Belgian coast into a parapet then gets lost. Overtopping reducing effects are similar.

\section{EXPERIMENTAL SET-UP}

Test facility and wave generation

All tests for this research were performed in the 2D wave flume of the Department of Civil Engineering at Ghent University. Dimensions of the flume are $\mathrm{L}=30.0 \mathrm{~m}, \mathrm{~W}=1.0 \mathrm{~m}$ and $\mathrm{H}=1.2 \mathrm{~m}$. Waves are generated using a piston type wave paddle, and the steering of this paddle features active wave absortion. The irregular waves were generated using mainly the Jonswap spectrum with peak enhancement factor $\gamma=3.3$. Some tests were repeated with a standard Pierson-Moskowitz spectrum, 
but no differences were found regarding wave overtopping. Each tested time series contained approximately 1000 waves, in order to obtain reliable average overtopping discharges.

\section{Measurements}

Waves are measured using resistance type wave gauges, positioned as shown in Figure 5: 2 in front of the wave paddle (active wave absorption), 3 at deeper water, and 3 in front of the structure. By means of these groups, incident and reflected wave conditions can be separated from each other and the incoming wave height can be determined, using the method by (Mansard \& Funke, 1980).

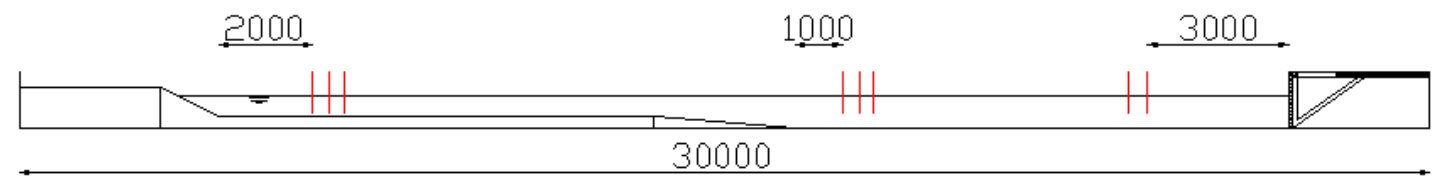

\section{Figure 5. Position of wave gauges in the 2D flume}

Wave overtopping is captured by a tray on top of the smooth dike, and lead to a basin that is constantly weighed on a balance. When the basin is full, water is pumped back to the wave flume in order to maintain the correct water level in the flume during the test. Total overtopping volume can be deducted from the balance's weight registration in time.

\section{TEST PROGRAM}

In this research, the wave overtopping over a smooth dike with parapet is compared to both overtopping over a vertical wall on a smooth dike, and overtopping over a normal smooth dike. The smooth dike acts as a reference case. Even though the smooth dike has already been studied by numerous authors, and well-known design formulas are available in literature, we have chosen to repeat a number of these tests in our flume. In this way, measuring devices and techniques are the same for the expansions as for the reference case, and a good comparison can be made. This leads to a reduction factor, expressing the reduction in wave overtopping by means of a parapet or vertical wall compared to a classical dike with the same crest height.

Conclusions of the research can only be drawn in the range of parameters which was tested. Using the design formulas outside these ranges may lead to wrong results.

\section{Smooth dike}

\begin{tabular}{|l|c|c|}
\hline Height foreshore (above bottom of the flume) & 0.25 & $\mathrm{~m}$ \\
\hline Crest height (above foreshore) & 0.62 & $\mathrm{~m}$ \\
\hline Crest height (above bottom flume) & 0.87 & $\mathrm{~m}$ \\
\hline Waterdepth at toe of the structure & $0.35-0.49$ & $\mathrm{~m}$ \\
\hline Waterdepth at the wave paddle & $0.60-0.74$ & $\mathrm{~m}$ \\
\hline Freeboard $\left(\mathrm{R}_{\mathrm{C}}\right)$ & $0.27-0.13$ & $\mathrm{~m}$ \\
\hline Wave height $\left(\mathrm{H}_{\mathrm{m} 0}\right)$ & $0.095-0.174$ & $\mathrm{~m}$ \\
\hline Wave peak period $\left(\mathrm{T}_{\mathrm{p}}\right)$ & $1.1-2.7$ & $\mathrm{~s}$ \\
\hline Wave steepness $\left(\mathrm{s}_{0}\right)$ based on $\mathrm{T}_{\mathrm{m}-1,0}$ & $0.015-0.06$ & - \\
\hline Dimensionless freeboard $\left(\mathrm{R}_{\mathrm{C}} / \mathrm{H}_{\mathrm{m} 0}\right)$ & $0.75-2.45$ & - \\
\hline
\end{tabular}

Table 1. Geometrical and hydraulic boundary conditions of the tests on a smooth dike $1(\mathrm{~V}) / 2(\mathrm{H})$

\section{Dike with vertical wall or parapet}

The geometrical boundary conditions were identical as in the reference case 'smooth dike'. The hydraulic parameters can differ, and are listed in Table 2.

\begin{tabular}{|l|c|c|}
\hline Waterdepth at toe of the structure & $0.36-0.57$ & $\mathrm{~m}$ \\
\hline Waterdepth at the wave paddle & $0.61-0.82$ & $\mathrm{~m}$ \\
\hline Freeboard $\left(\mathrm{R}_{\mathrm{C}}\right)$ & $0.26-0.05$ & $\mathrm{~m}$ \\
\hline Wave height $\left(\mathrm{H}_{\mathrm{m} 0}\right)$ & $0.068-0.180$ & $\mathrm{~m}$ \\
\hline Wave peak period $\left(\mathrm{T}_{\mathrm{p}}\right)$ & $1.045-2.44$ & $\mathrm{~s}$ \\
\hline Wave steepness $\left(\mathrm{s}_{0}\right)$ based on $\mathrm{T}_{\mathrm{m}-1,0}$ & $0.013-0.052$ & - \\
\hline Dimensionless freeboard $\left(\mathrm{R}_{\mathrm{C}} / \mathrm{H}_{\mathrm{m} 0}\right)$ & $0.6-2.65$ & - \\
\hline
\end{tabular}

Table 2. Hydraulic boundary conditions for the tests with vertical wall and parapet

The parameters used in this research can be up scaled to prototype values using Froude scaling law. 


\section{ANALYSES}

To calculate wave overtopping over dikes, the eurotop manual prescribes the so-called van der Meer approach (TAW 2002, Eurotop 2007). A distinction is made between breaking and non-breaking waves, which is based on the Irribaren number. In both cases the dimensionless overtopping rate is given as a function of a dimensionless freeboard:

$$
\begin{gathered}
Q^{*}=a \cdot \exp \left(-b \cdot R^{*}\right) \\
\text { For breaking waves: } \frac{q}{\sqrt{g \cdot H_{m 0}^{3}}}=\frac{0.067}{\sqrt{\tan \alpha}} \cdot \xi_{0} \cdot \gamma_{b} \cdot \exp \left(-4.75 \cdot \frac{R_{C}}{H_{m 0}} \cdot \frac{1}{\xi_{0} \cdot \gamma_{b} \cdot \gamma_{f} \cdot \gamma_{\beta} \cdot \gamma_{v}}\right)
\end{gathered}
$$

For non-breaking waves: $\frac{q}{\sqrt{g \cdot H_{m 0}^{3}}}=0.2 \cdot \exp \left(-2.6 \cdot \frac{R_{C}}{H_{m 0}} \cdot \frac{1}{\gamma_{f} \cdot \gamma_{\beta}}\right)$

In these formulas, $\mathrm{q}$ stands for average overtopping discharge per $\mathrm{m} ; \mathrm{g}=$ acceleration due to gravity; $\mathrm{H}_{\mathrm{m} 0}=$ incident spectral wave height; $\mathrm{R}_{\mathrm{c}}=$ freeboard; $\xi_{0}=$ Irribaren number $=$ breaker parameter $=\tan \alpha / \mathrm{s}_{0}{ }^{0.5} ; \tan \alpha=$ structure's slope; $\mathrm{s}_{0}=$ wave steepness $=2 . \pi \cdot \mathrm{H}_{\mathrm{m} 0} /\left(\mathrm{g} \cdot \mathrm{T}_{\mathrm{m}-1,0^{2}}\right) ; \mathrm{T}_{\mathrm{m}-1,0}=$ spectral wave period; $\gamma=$ reduction factor due to the slope roughness $\left(\gamma_{\mathrm{f}}\right)$, angle of incident wave $\left(\gamma_{\beta}\right)$, existence of a berm $\left(\gamma_{b}\right)$ or vertical wall $\left(\gamma_{v}\right)$. These reduction factors give a virtual raise of the freeboard, which results in a reduction of wave overtopping over the coastal structure. Since we only test perpendicular wave impact $\left(\gamma_{\beta}=1\right)$ on smooth slopes $\left(\gamma_{\mathrm{f}}=1\right)$ without berm $\left(\gamma_{\mathrm{b}}=1\right)$, the van der Meer (vdM) formulas for wave overtopping over smooth dikes become

$$
\begin{gathered}
\frac{q}{\sqrt{g \cdot H_{m 0}^{3}}}=\frac{0.067}{\sqrt{\tan \alpha}} \cdot \xi_{0} \cdot \exp \left(-4.75 \cdot \frac{R_{C}}{H_{m 0}} \cdot \frac{1}{\xi_{0} \cdot \gamma_{v}}\right) \text { for breaking waves } \\
\frac{q}{\sqrt{g \cdot H_{m 0}^{3}}}=0.2 \cdot \exp \left(-2.6 \cdot \frac{R_{C}}{H_{m 0}}\right) \text { for non-breaking waves }
\end{gathered}
$$

Plotting such data gives a straight line in a log-linear plot. There is no reduction for the presence of vertical walls in case of non-breaking waves, according to the vdM-formula. This will be discussed further on in this paper.

The lower a reduction factor $\gamma$ is, the better reduction is achieved since the overtopping discharge reduces.

\section{RESULTS FOR NON-BREAKING WAVES}

\section{Reference case: smooth dike}

51 tests with non-breaking waves $\left(\xi_{0}>\sim 2\right)$ on a smooth dike with slope $1(\mathrm{~V}) / 2(\mathrm{H})$ have been executed as reference data set. When all these tests are plotted in the log-linear diagram, a similar but slightly higher trend compared with formula (5) by van der Meer is obtained.

$$
Q^{*}=0.2 \cdot \exp (-2.335 \cdot R *)
$$

Reduction factors for vertical wall and parapet will be referred to this reference case, not to the traditional vdM formulas. The b-coefficient (eq (1)) of the reference case is 2.335 . 


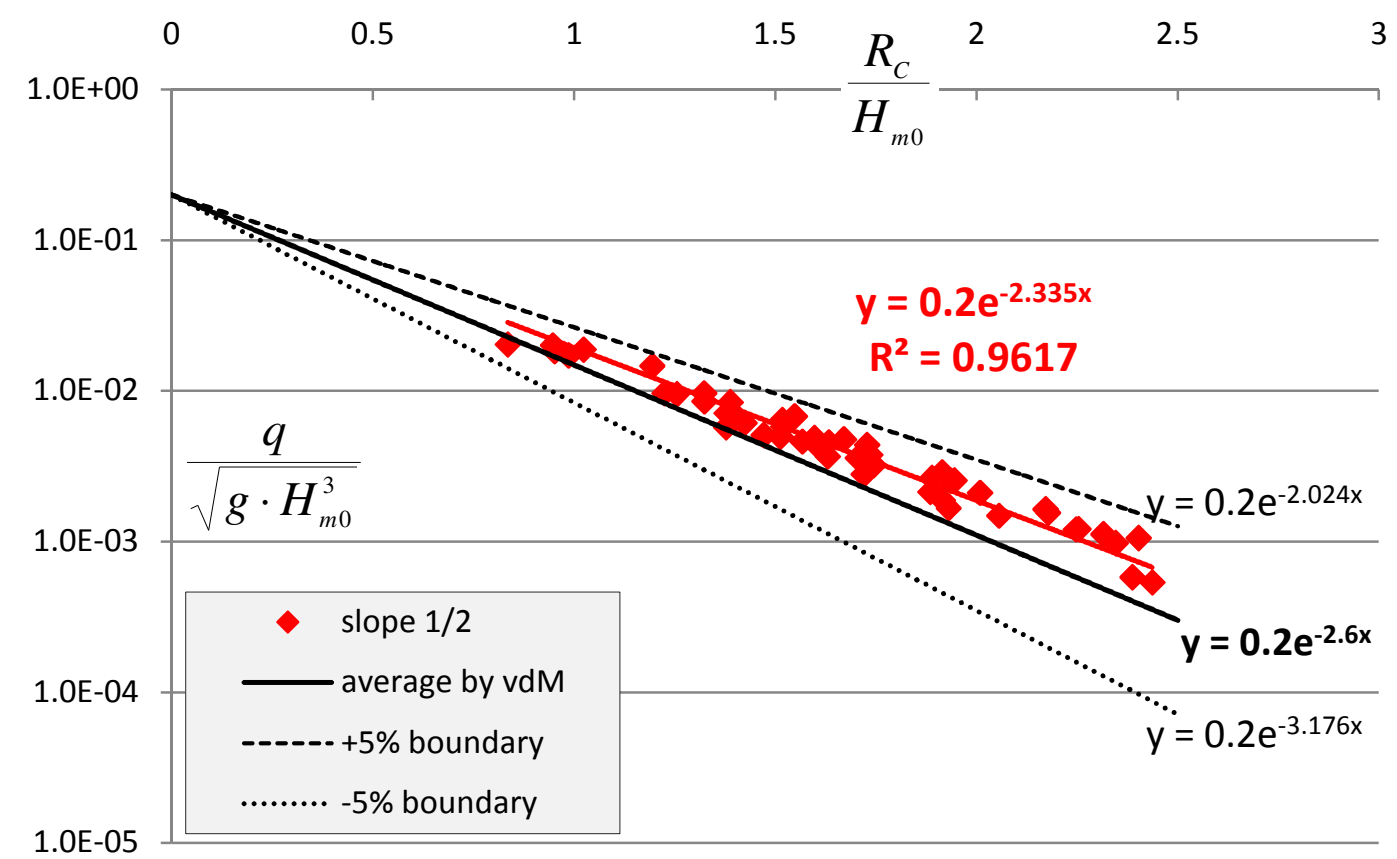

Figure 6. Dimensionless overtopping discharges as a function of the dimensionless freeboard for nonbreaking waves over smooth dike: reference data set

Smooth dike with vertical wall

7. Geometry of a vertical wall built in the dike

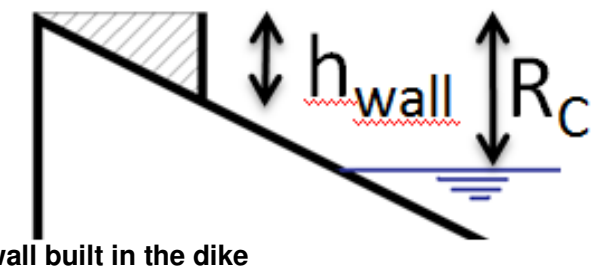

Several vertical walls, with different height $\left(\mathrm{h}_{\text {wall }}=2-4-5-6-8 \mathrm{~cm}\right)$, have been built into the dike with slope $1 / 2$, with the same crest height as shown on Figure 7. 88 tests have been performed and plotted in Figure 8 grouped by the height of the wall.

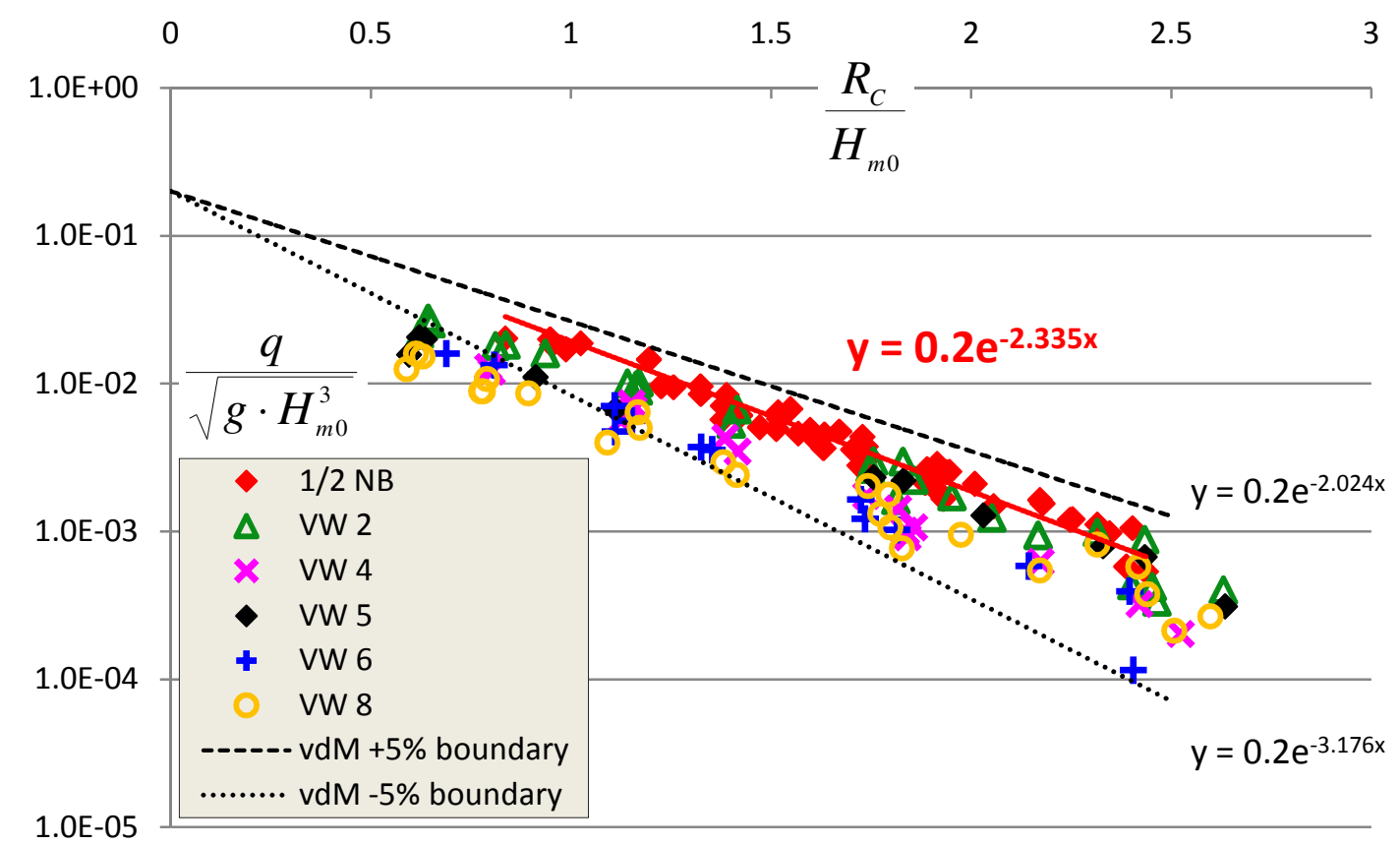

Figure 8. Dimensionless overtopping versus dimensionless freeboard: reference data set (red), vertical wall (green $2 \mathrm{~cm}$, pink $4 \mathrm{~cm}$, black $5 \mathrm{~cm}$, blue $6 \mathrm{~cm}$, orange $8 \mathrm{~cm}$ ) 
The 88 tests on a smooth dike with vertical wall are plotted together with the reference situation (red data) smooth dike on Figure 8. In order not to overload the graph, the vdM-line has been left out, but the $90 \%$ confidence band is drawn as visual help.

It can clearly be seen that a vertical wall has its influence on the wave overtopping: the data points for the tests with vertical wall (green, pink, black, blue and orange in Figure 8) lie below the data from the reference situation without vertical wall (red data in Figure 8). These findings contradict with the eurotop guidelines, who say there is no $\gamma_{v}$ necessary for non-breaking waves (eq. (3)).

Another remarkable fact is the influence of the wall height on the reduction. The green data points, vertical wall of $2 \mathrm{~cm}$ height, lie below the red reference data. The pink (vertical wall $4 \mathrm{~cm})$, black $(5 \mathrm{~cm})$, blue $(6 \mathrm{~cm})$ and orange $(8 \mathrm{~cm})$ are lying even a bit lower in the graph. The higher the wall, the lower the wave overtopping, which is also in contrast with the $\gamma_{\mathrm{v}}$-formula for breaking waves which is independent of the wall height (TAW 2002, Eurotop 2007).

We have left the traditional analysis path of dividing 2.335 (the b-coefficients of the reference case formula (6)) by the b-coefficients of the data grouped by the dimensionless wall height $\left(\mathrm{h}_{\text {wall }} / \mathrm{R}_{\mathrm{C}}\right.$ or $\mathrm{h}_{\mathrm{wall}} / \mathrm{H}_{\mathrm{m} 0}$ ) to obtain reduction factors $\gamma$. Here, we have calculated a $\gamma_{\mathrm{v}}$ needed to shift every singular data point to the reference line $\mathrm{Q}^{*}=0.2 \exp \left(-2.335 \mathrm{R}^{*}\right)$. The best correlation can be found when plotting these values versus the dimensionless wall height $\left(h_{\text {wall }} / R_{C}\right)$, as shown in Figure 9.

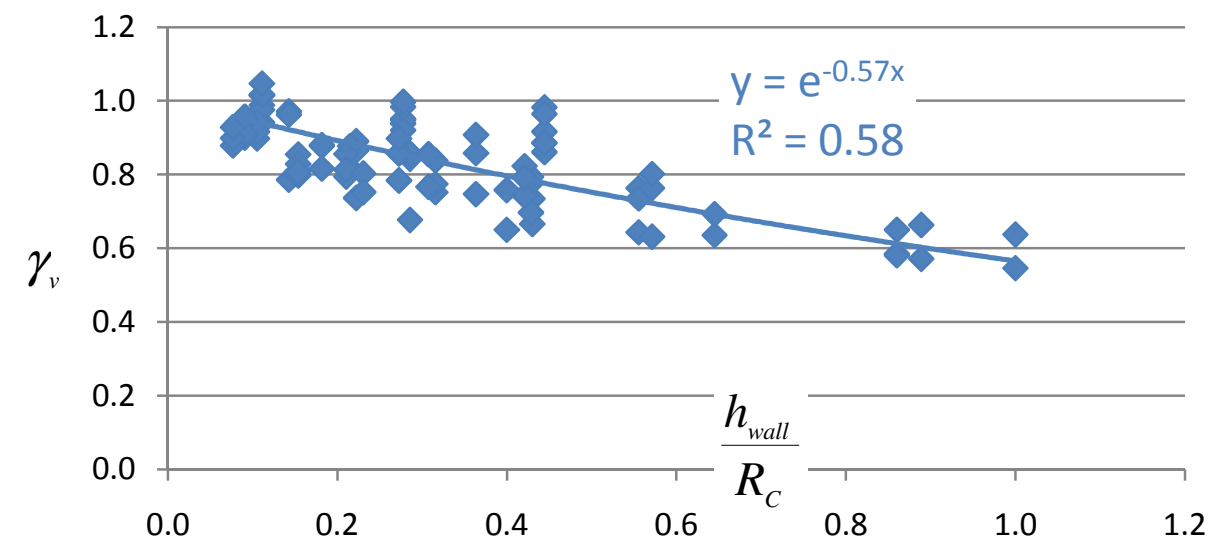

Figure 9. Reduction factor $\gamma_{v}$ of every point versus dimensionless wall height.

An exponential descending trend can be seen in the data points of Figure 9, with equation

$$
\gamma_{v}=\exp \left(-0.57 \cdot \frac{h_{\text {wall }}}{R_{C}}\right)
$$

Without wall $\left(\mathrm{h}_{\text {wall }}=0\right)$, this expression leads to $\gamma_{\mathrm{v}}=1$ : no reduction compared to the smooth dike. The range of $h_{\text {wall }} / R_{C}$ is limited to 1 , since other physical behavior will occur when the still water line $(\mathrm{SWL})$ reaches the wall $\left(\mathrm{h}_{\mathrm{wall}} / \mathrm{R}_{\mathrm{C}}>1\right)$.

A data plot like Figure 8 can now be repeated, with the inclusion of the obtained reduction factor (eq. (7)) on the abscissa.

The single calculated $\gamma_{v}$ 's were only defined to find a trend between $\gamma_{v}$ and the dimensionless $h_{\text {wall }} / R_{C}$. Further on, we will always use the obtained trend (7). The result can be seen in Figure 10. 


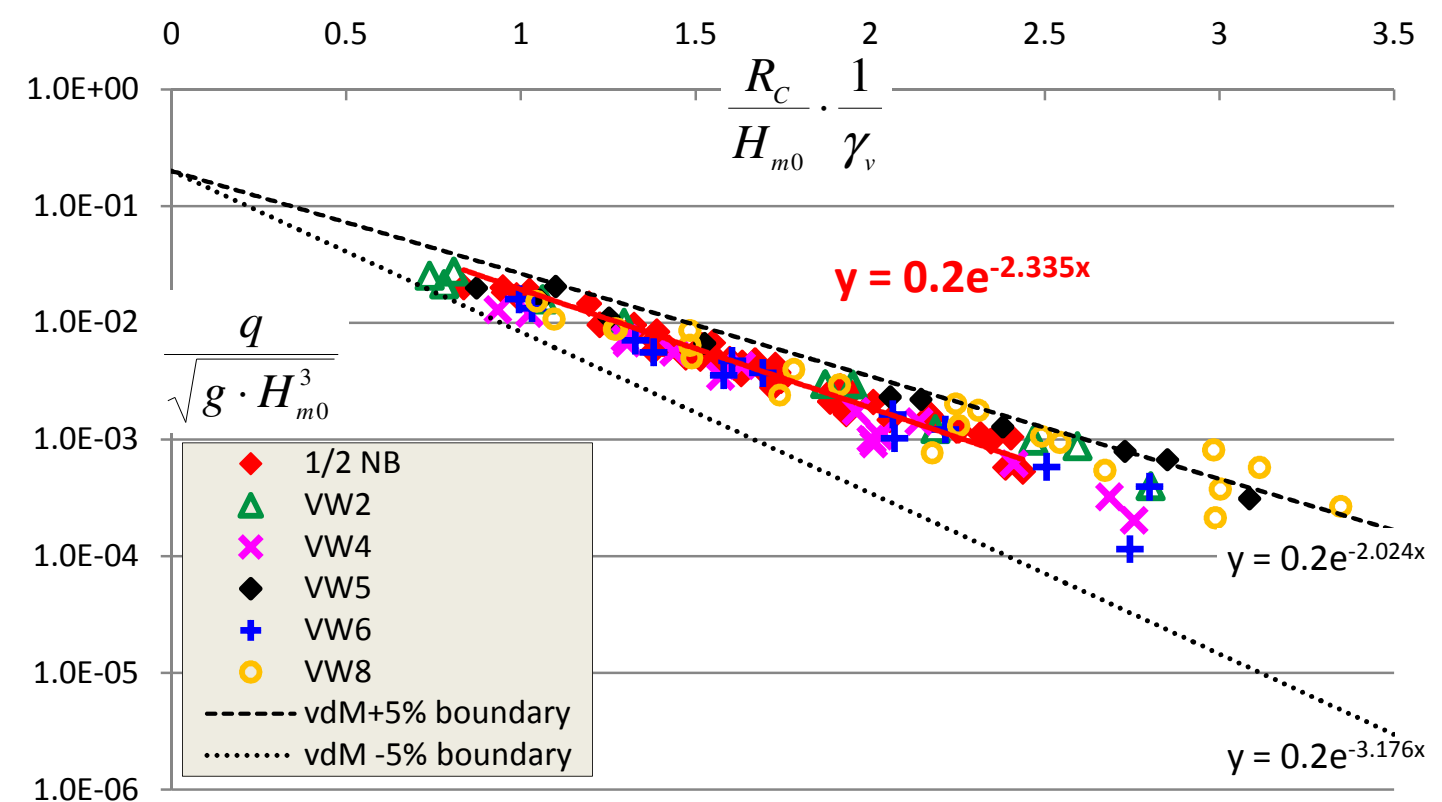

Figure 10. The obtained data with inclusion of $\gamma_{v}$ in the dimensionless freeboard are lying closer to the red reference line.

Wave overtopping on smooth dikes with a vertical wall is well predicted by the formula

$$
\frac{q}{\sqrt{g \cdot H_{m 0}^{3}}}=0.2 \cdot \exp \left(-2.335 \cdot \frac{R_{C}}{H_{m 0}} \cdot \frac{1}{\gamma_{v}}\right)
$$

\section{SMOOTH DIKE WITH PARAPET}

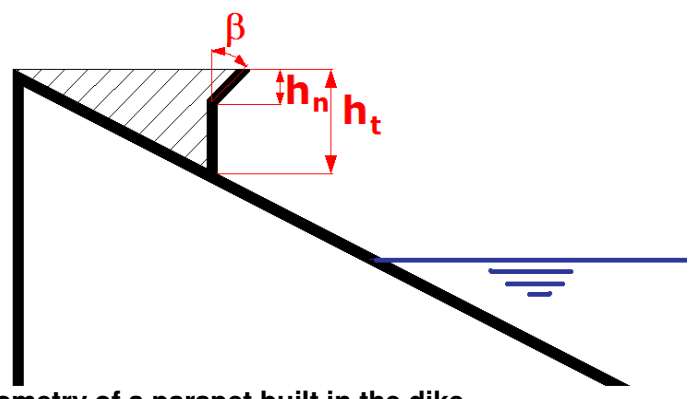

$$
\lambda=\frac{h_{n}}{h_{\text {tot }}}
$$

Figure 11. Geometry of a parapet built in the dike.

Only small modifications have been made to the vertical wall to optimize the reduction of wave overtopping. A nose has been added to the wall, but the crest height of the original dike again remains the same. In this paper, the influence of the angle $\beta$ and the height ratio $\lambda=\mathrm{h}_{\mathrm{n}} / \mathrm{h}_{\mathrm{t}}$ has been studied (Figure 11). In total 92 test with different geometrical combinations were executed in the wave flume: the total parapet height $\left(h_{t}\right)$ was 2,5 or $8 \mathrm{~cm}$, the angle $\beta$ was $15^{\circ}, 30^{\circ}, 45^{\circ}$ or $60^{\circ}$ and $\lambda$ had a value in between $1 / 8$ and 1 .

Not all data points will be plotted here, since this would create an overload of data points in the graph. An example of the analysis will be shown for the parapet $h_{t}=5 \mathrm{~cm}$. 


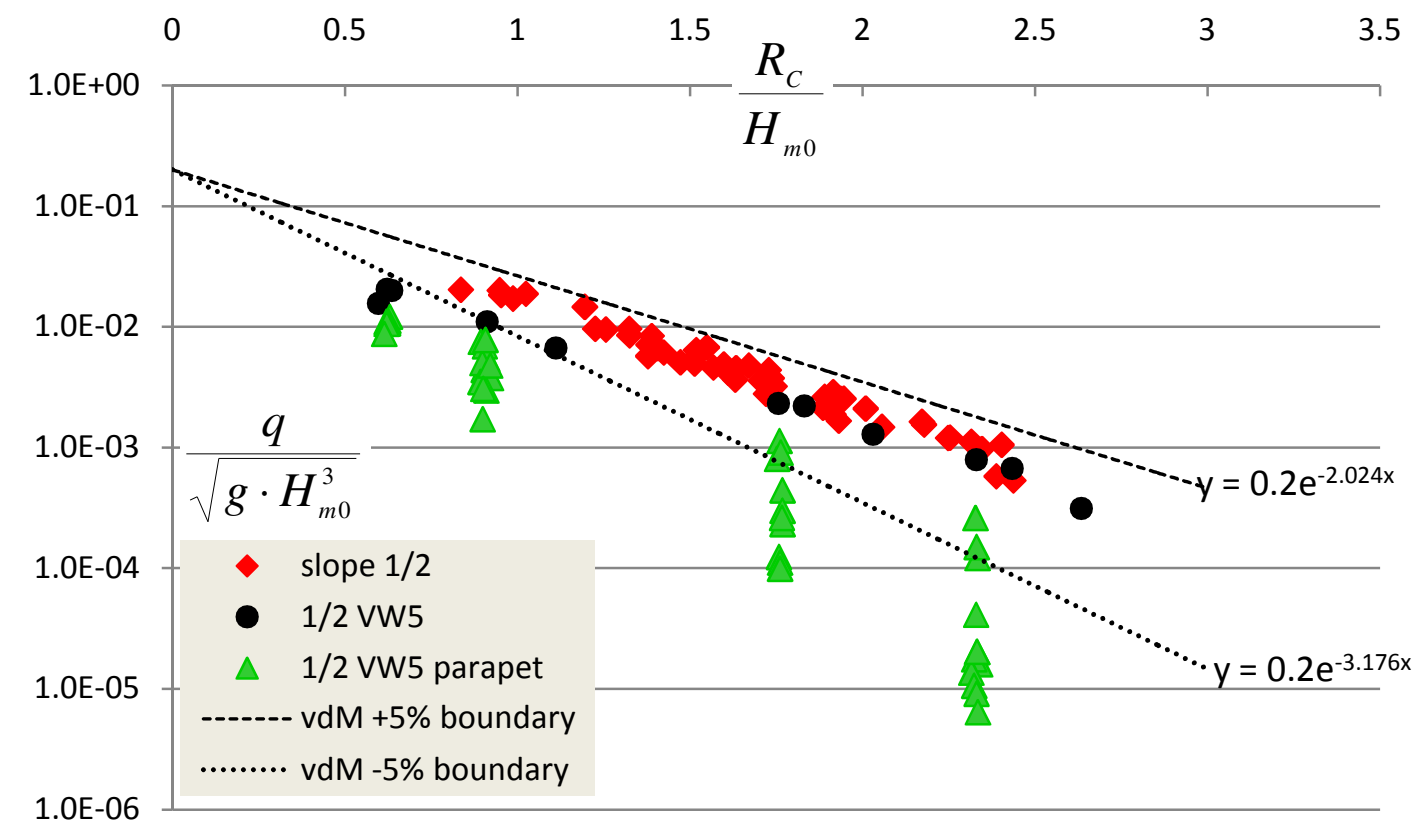

Figure 12. Dimensionless overtopping versus dimensionless freeboard: reference data (red), vertical wall of $5 \mathrm{~cm}$ high (black) and parapet of $5 \mathrm{~cm}$ high (green)

We see a major reduction due to the nose of the parapet, since all green data points on Figure 12 lie below the red (smooth dike) and black (vertical wall) data points. A reduction factor $\gamma_{\text {par }}$ should be introduced in the exponential part of formula (8). This reduction factor describes the behavior of the parapet's nose related to the vertical wall without nose. Higher, a reduction factor for a vertical wall has already been introduced (eq. (7)). Multiplication of both reduction factors (wall, parapet), will give the full reduction of a parapet compared to a smooth dike. $\gamma_{\text {par }}$ on its own will only give the influence of adding a nose to the wall, so creating a parapet.

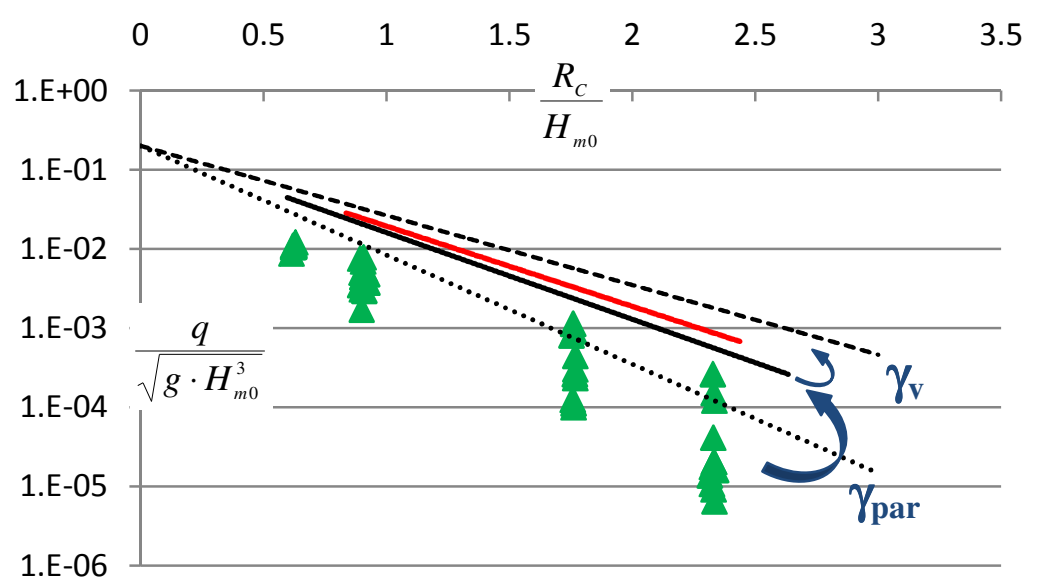

Figure 13. Definition of $\gamma_{\text {par }}$ and $\gamma_{v}$

Seeing the scatter amongst the green data, $\gamma_{\text {par }}$ will most probably be a function of more than one geometrical parameter. Influences of both the angle of the parapet's nose $(\beta)$ and the dimensionless height of the parapet's nose $(\lambda)$ will be investigated. The contribution of each parameter to the reduction of overtopping can not be separated. Isolating just one parameter will still contain the influences of the other parameter.

To find $\gamma_{\text {par }}$, the vertical wall without nose will be the reference case. 


\section{Influence of nose angle $\beta$}

First, all data are grouped by their angle $\beta$, to investigate the influence of the parapet's nose.

0.5 1

1.5 2

2.5

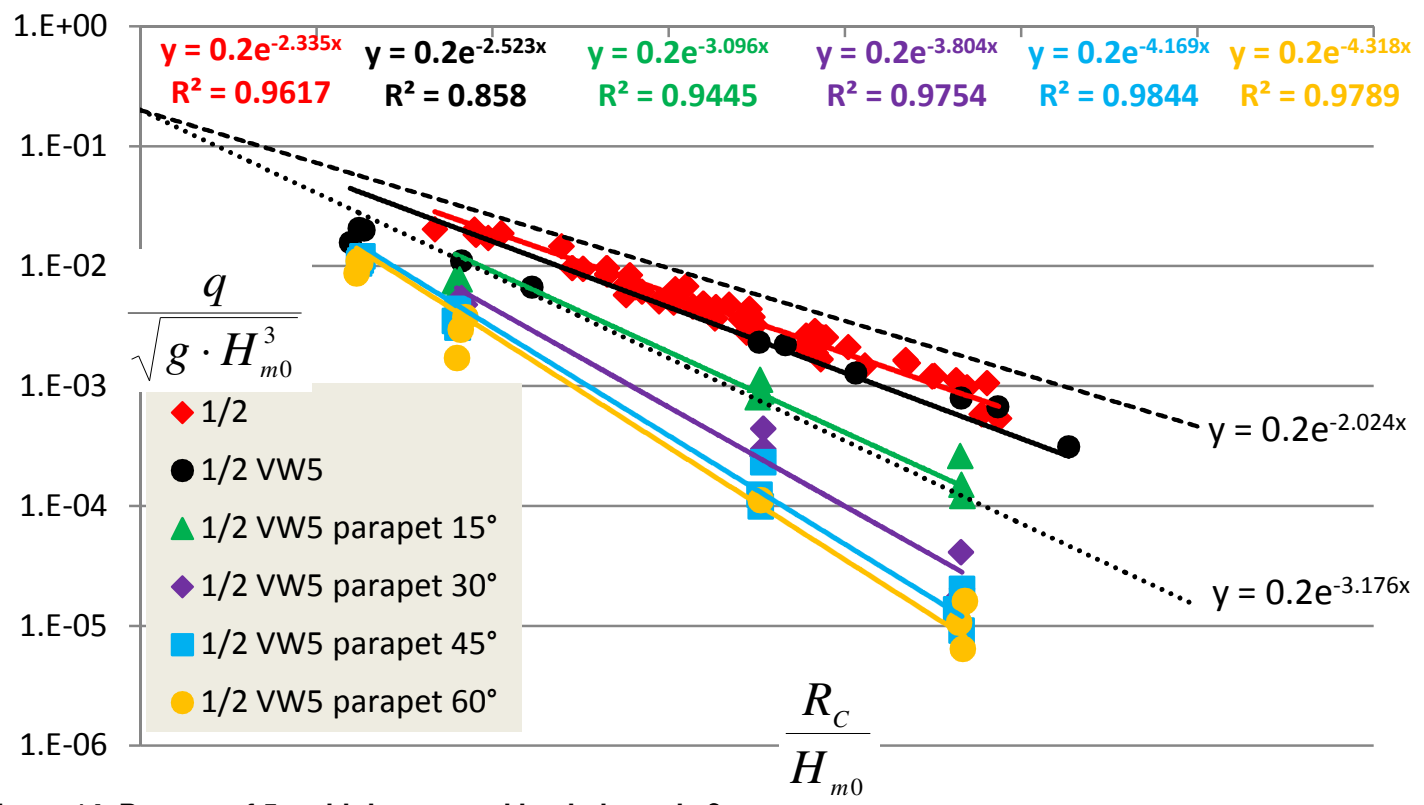

Figure 14. Parapet of $5 \mathrm{~cm}$ high, grouped by their angle $\beta$

If reduction factors $\gamma_{\beta}$ are now calculated in the traditional way, by dividing the value $b=2.523$ $(y=0.2 \exp (-2.523 x)$, equation of the black reference line of the vertical wall $5 \mathrm{~cm})$ by the $b$-values of the different parapet trendlines. All calculated $\gamma_{\beta}$-values for this example are plotted in Figure 15 (blue diamonds). An analogue analysis has been made for all parapets of $8 \mathrm{~cm}$ high (Figure 15, red crosses),

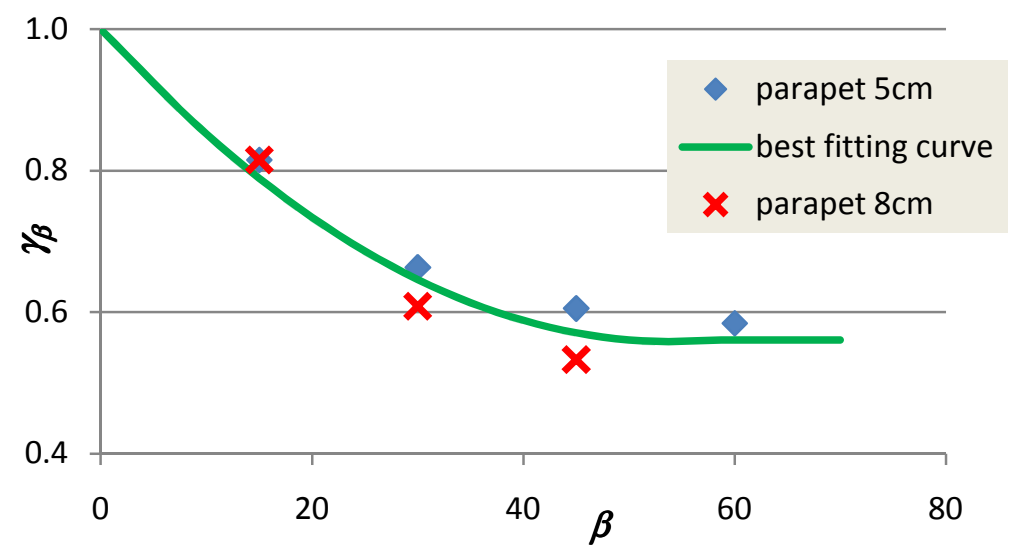

Figure 15. Reduction factor $\gamma_{\beta}$ due to the angle $\beta$, for all parapets of $5 \mathrm{~cm}$ and $8 \mathrm{~cm}$ high.

The green curve is the best fitting curve for these data: a quadratic descending function up to $\beta=$ $50^{\circ}$. From that point on, no profit can be achieved by increasing the parapet nose angle. The curve passes through $\gamma_{\beta}=1$ for $\beta=0^{\circ}$, i.e. no nose so no reduction of overtopping compared to a vertical wall. The function description of the green trendline in Figure 15 is

$$
\left\{\begin{array}{lll}
\gamma_{\beta}=1.53 \cdot 10^{-4} \cdot \beta^{2}-1.63 \cdot 10^{-2} \cdot \beta+1 & \text { for } & \beta \leq 50^{\circ} \\
\gamma_{\beta}=0.561 & \text { for } & \beta \geq 50^{\circ}
\end{array}\right.
$$

At last, an analogue analysis has been made for all parapets of $h_{\text {tot }}=2 \mathrm{~cm}$. The height of the nose $h_{n}$ was $1 \mathrm{~cm}$ or $2 \mathrm{~cm}$, leading to $\lambda=0.5$ or 1 . Visual observation during the experiments and data analysis have shown that this low parapet physically behaves different compared to higher parapets. The upward projection of the incoming wave gets lost and waves overtop more easily. The above equation (10) is only valid for $h_{\text {tot }} / R_{C}>0.25$, while parapets of $2 \mathrm{~cm}$ high will be treated further in this paper. 
Influence of dimensionless nose height $\lambda$

If we have a closer look at Figure 14, the scatter amongst the data points of 1 angle (for example $\beta$ $=60^{\circ}$, yellow dots) is still too big. This means there is another geometrical parameter, apart from angle $\beta$, influencing the physical behavior. As explained before, we can now group all data points of Figure 12 by the second geometrical variable of the parapet: the height ratio $\lambda$, which is a dimensionless representation of the height of the parapet's nose. This leads to Figure 16. The higher the $\lambda$-value, the lower the overtopping rate, the higher the reduction.

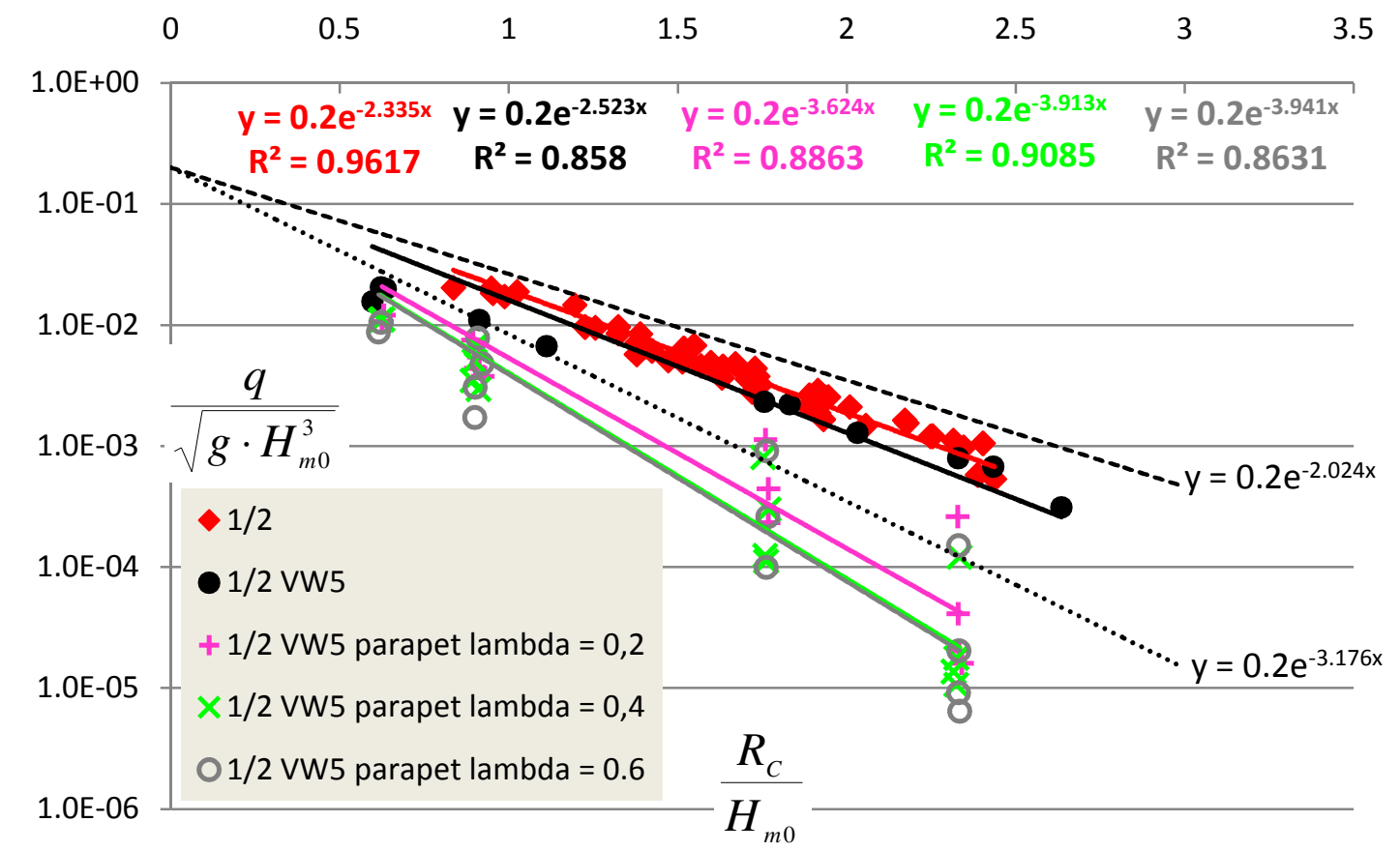

Figure 16. Parapet of $5 \mathrm{~cm}$ high, grouped by the dimensionless height of the nose: $\lambda$

The traditional way of analyzing leads to reduction factors $\gamma_{\lambda}$, again referred to the vertical wall. If the calculated $\gamma_{\lambda}$ values of all data points of parapets of $5 \mathrm{~cm}$ are now plotted together with $\gamma_{\lambda}$ obtained from parapets of $8 \mathrm{~cm}$, Figure 17 is obtained.

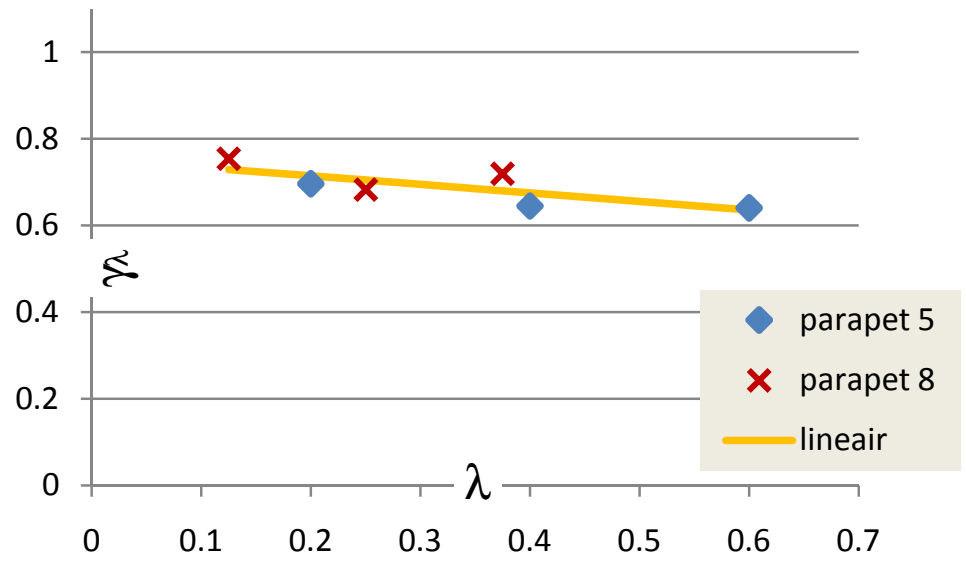

Figure 17. Reduction factor $\gamma_{\lambda}$ due to the height ratio $\lambda$, for all parapets of $5 \mathrm{~cm}$ and $8 \mathrm{~cm}$ high.

Parapets of $5 \mathrm{~cm}$ are represented in blue diamonds, while red crosses show parapets of $8 \mathrm{~cm}$. As mentioned before, parapets of $2 \mathrm{~cm}$ high react different on the incoming wave, and will be treated later in this paper.

A linear slightly descending trend between $\lambda=0.125$ and 0.6 is the best description for the calculated values of $\gamma_{\lambda}$ (orange trend line in Figure 17). If $\lambda=0$, meaning there is no nose, there is no reduction compared to the vertical wall, leading to $\gamma_{\lambda}=1$. 
For $h_{\text {tot }} / R_{C}>0.25$, the function description of $\gamma_{\lambda}$ now becomes

$$
\begin{cases}\gamma_{\lambda}=0.754-0.198 \cdot \lambda & \text { for } \quad \lambda \in[0.125-0.6] \\ \gamma_{\lambda}=1 & \text { for } \quad \lambda=0\end{cases}
$$

For smaller parapets with $h_{\text {tot }} / R_{C} \leq 0.25$ the incoming wave is projected less upward, and hence less seaward. The crest will be overtopped more. Design formulas for $h_{t o t} / R_{C} \leq 0.25$ are for completeness added in a flowchart in the last paragraph of the paper.

\section{$\gamma_{p a r}$ as a function of $\gamma_{\beta}$ and $\gamma_{\lambda}$}

Due to the scatter of the data grouped by the geometrical parameters $\beta$ (Figure 14) and $\lambda$ (Figure 16), it becomes clear that individual parameters are not sufficient to describe the process of overtopping reduction by means of a parapet. On the other hand, both geometrical variables are dependent of each other. This means the influence of $\beta$ is involved in $\gamma_{\lambda}$ and the influence of $\lambda$ is involved in $\gamma_{\beta}$. The multiplication of both will therefore overestimate the reduction

For each individual data point $\gamma_{\mathrm{par}}$ has been calculated similar as for $\gamma_{\mathrm{v}}$ : what component should be added to the exponential part of formula (8) to shift the data point to the reference line of the smooth dike. These values (for $h_{w a l l} / R_{C}>0.25$ ) can now be compared with the product $\gamma_{\beta} \cdot \gamma_{\lambda}$ in Figure 18 .

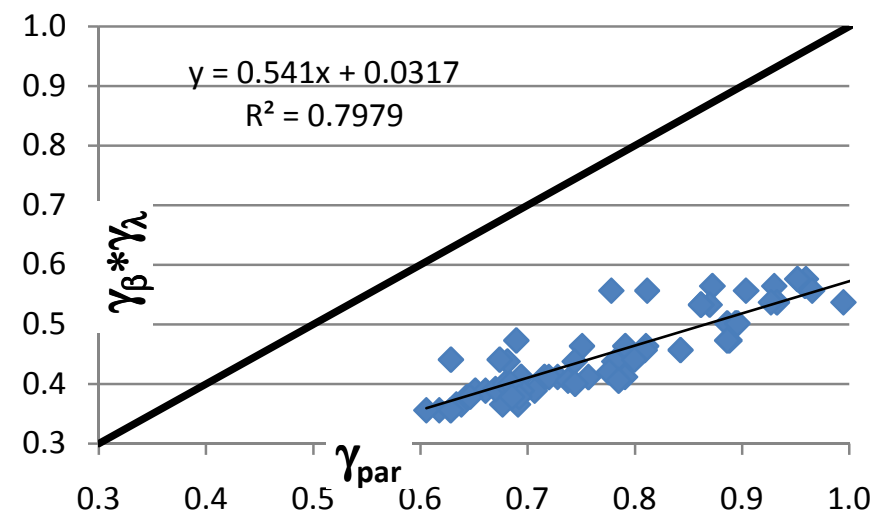

Figure 18. Relation between $\gamma_{\mathrm{par}}$ and $\gamma_{\beta}{ }^{*} \gamma_{\lambda}$

As predicted, multiplying $\gamma_{\beta}$ and $\gamma_{\lambda}$ is an overestimation of the true reduction: $\gamma_{\beta} \cdot \gamma_{\lambda}$ is much lower than $\gamma_{\mathrm{par}}$. Figure 18 also shows the existence of a linear trend through the data points, leading to the function description of $\gamma_{\mathrm{par}}$ as a function of $\gamma_{\beta}$ and $\gamma_{\lambda} . \gamma_{\mathrm{par}}$ has an upper limit, $\gamma_{\mathrm{par}}=1$.

$$
\gamma_{\text {par }}=\frac{\left(\gamma_{\beta} \cdot \gamma_{\lambda}-0.0317\right)}{0.541} \approx 1.8 \cdot \gamma_{\beta} \cdot \gamma_{\lambda}
$$

If both deducted formulas of the dimensionless reduction factors $\gamma_{v}(7)$ and $\gamma_{\text {par }}$ (12) are now introduced in the exponential part of the traditional vdM overtopping formula for non-breaking waves, this formula becomes

$$
\frac{q}{\sqrt{g \cdot H_{m 0}^{3}}}=0.2 \cdot \exp \left(-2.335 \cdot \frac{R_{C}}{H_{m 0}} \cdot \frac{1}{\gamma_{v} \cdot \gamma_{p a r}}\right)
$$

and can be used to calculate the overtopping discharge over a smooth dike with vertical wall or parapet. 


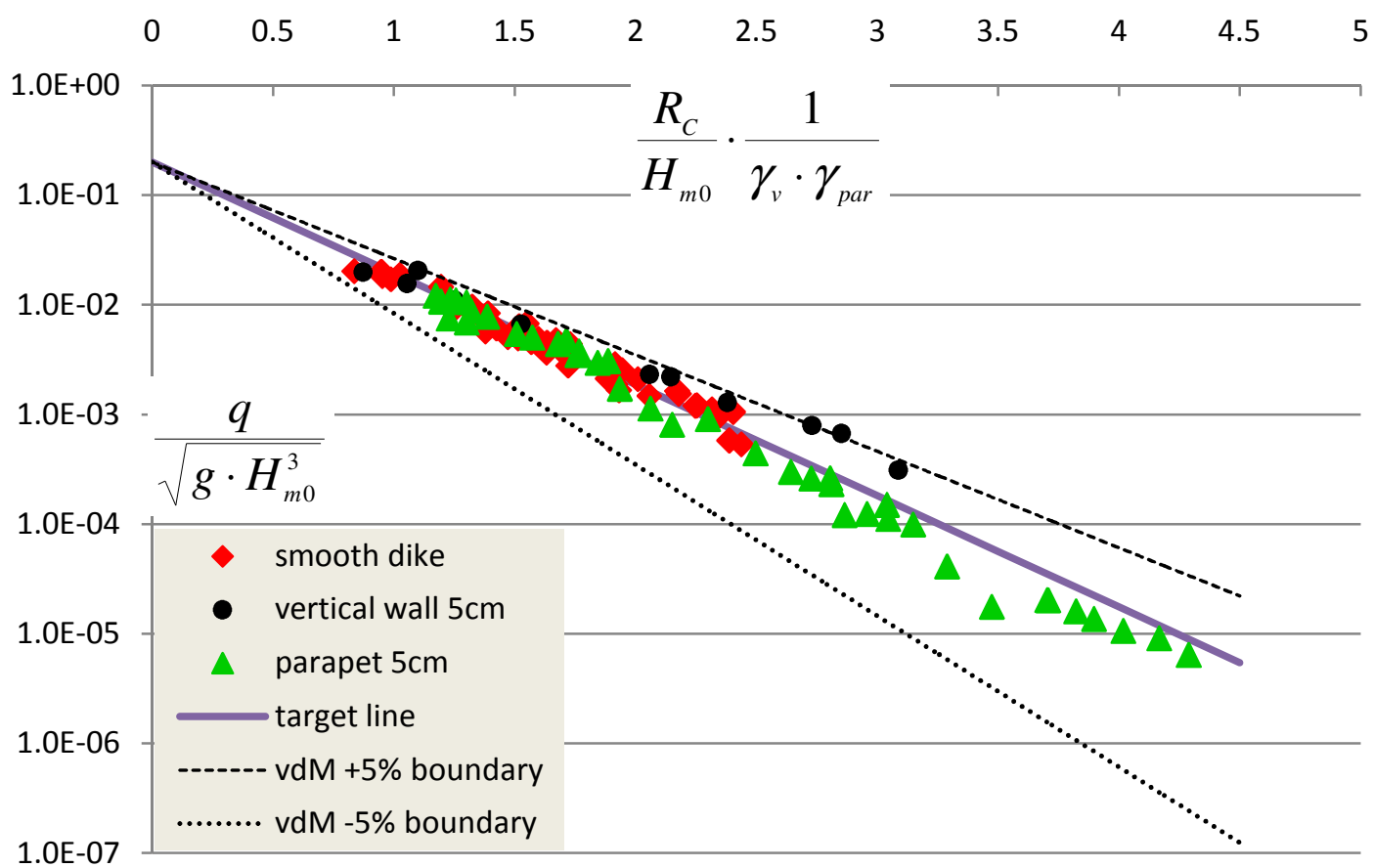

Figure 19. Better prediction from the obtained data (parapet $5 \mathrm{~cm}$ and vertical wall $5 \mathrm{~cm}$ ) with inclusion of $\gamma_{v}$ and $\gamma_{p a r}$ in the dimensionless freeboard.

When comparing Figure 19 with Figure 12, the scatter of the data points around the target line $\mathrm{y}=$ $0.2 \exp (-2.335 \mathrm{x})$ has been reduced significantly by introducing $\gamma_{\mathrm{v}}$ and $\gamma_{\mathrm{par}}$ on the abscissa of this plot. The adapted vdM formula for non-breaking waves is now able to predict wave overtopping over smooth dikes with vertical wall or parapets if $h_{\text {wall }} / R_{C}>0.25$.

In case of a low dimensionless wall height $\left(\mathrm{h}_{\text {wall }} / \mathrm{R}_{\mathrm{C}} \leq 0.25\right)$, the reduction factor $\gamma_{\text {par }}$ has been analyzed and is slightly higher (causing less reduction) than for the higher parapets. Formulas for $\gamma_{\text {par }}$ in case of $h_{\text {wall }} / R_{C} \leq 0.25$ are presented in the flowchart.

\section{FLOWCHART TO INCORPORATE REDUCTION FOR VERTICAL WALL AND PARAPET}

This research has lead to the use of formula (14) when calculating overtopping rates over smooth dikes with vertical wall or parapets.

$$
\frac{q}{\sqrt{g \cdot H_{m 0}^{3}}}=0.2 \cdot \exp \left(-2.335 \cdot \frac{R_{C}}{H_{m 0}} \cdot \frac{1}{\gamma_{v} \cdot \gamma_{p a r}}\right)
$$

The use of $\gamma_{v}$ and $\gamma_{\text {par }}$ depends on the (dimensionless) height of the vertical wall or parapet $h_{\text {wall }} / R_{C}$ and is summarized in the flowchart below 


$$
\begin{aligned}
& \Longrightarrow \gamma_{v}=\exp \left(-0.57 \cdot \frac{h_{\text {wall }}}{R_{C}}\right)
\end{aligned}
$$

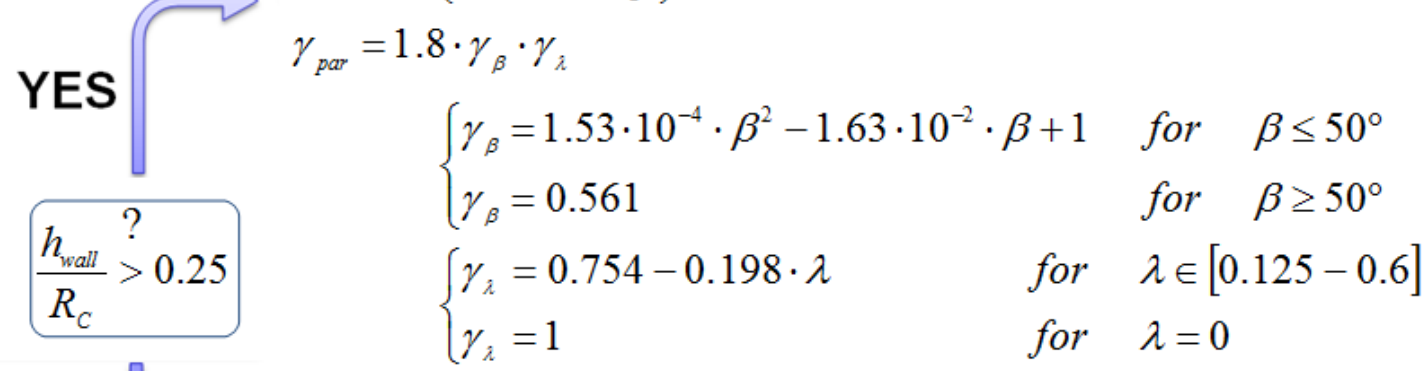

$$
\begin{aligned}
& \text { NO } \\
& \gamma_{v}=\exp \left(-0.57 \cdot \frac{h_{\text {wall }}}{R_{C}}\right) \\
& \gamma_{p a r}=1.8 \cdot \gamma_{\beta} \cdot \gamma_{\lambda}-0.53 \\
& \gamma_{\beta}=1-0.0029 \cdot \beta \\
& \text { for } \beta \leq 60^{\circ} \\
& \gamma_{\lambda}=1-0.1449 \cdot \lambda \\
& \text { for } \lambda \in[0-1]
\end{aligned}
$$

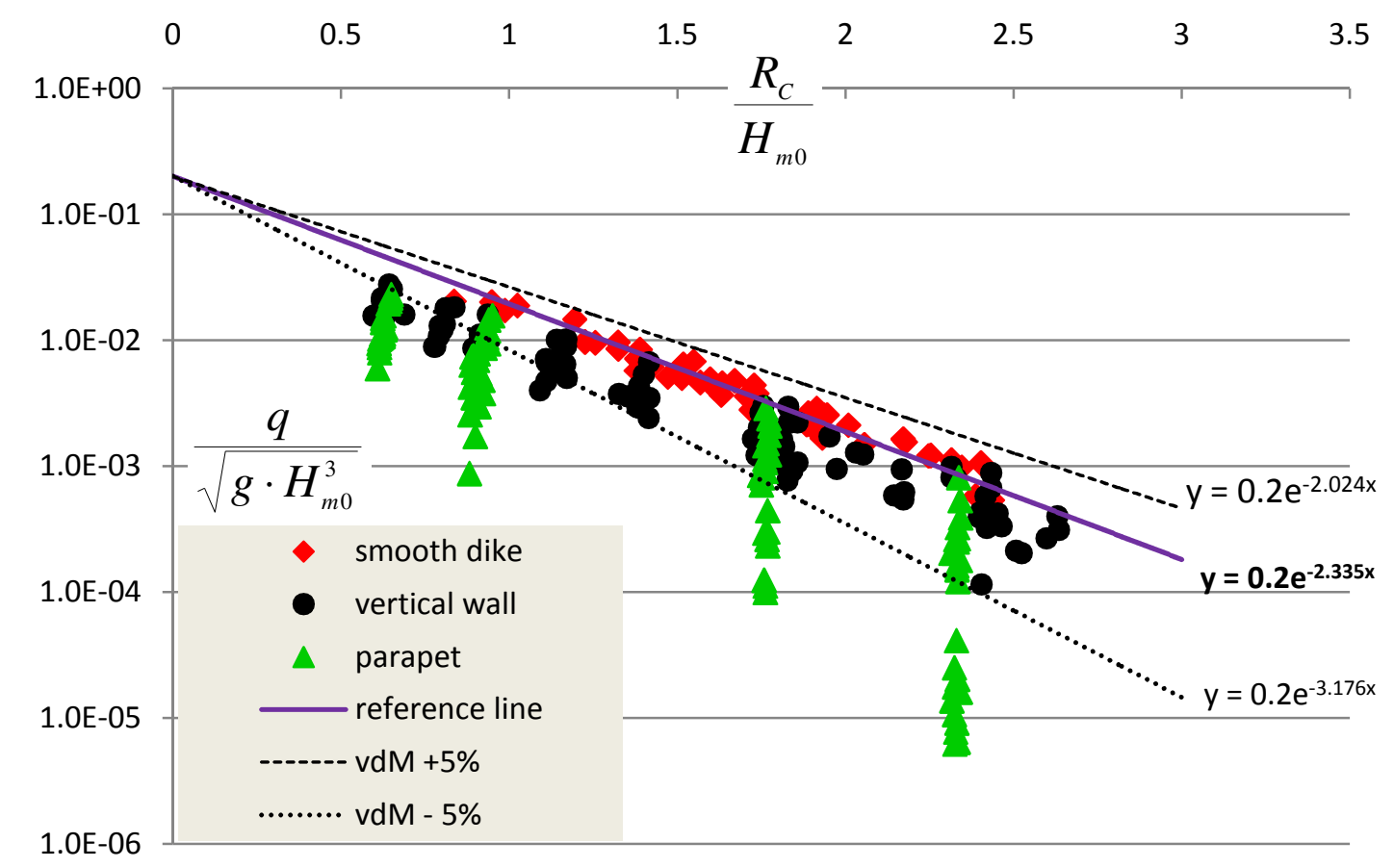

Figure 20. All data in a standard dimensionless semi logarithmic diagram

All data of this research are plotted in a standard log-linear diagram (dimensionless overtopping rate $\mathrm{q} /\left(\mathrm{g} . \mathrm{Hm} 0^{3}\right)^{1 / 2}$ on the $\mathrm{Y}$-axis and dimensionless freeboard $\mathrm{R}_{\mathrm{C}} / \mathrm{H}_{\mathrm{m} 0}$ on the $\mathrm{X}$-axis) in Figure 20 . The reduction of vertical walls (black) and parapets (green) versus the normal smooth dike is manifest. The purple line $\mathrm{y}=0.2 \exp \left(-2.335^{*} \mathrm{x}\right)$, the standard equation to calculate overtopping for non-breaking waves, does not give a good description for the black and green data points. 


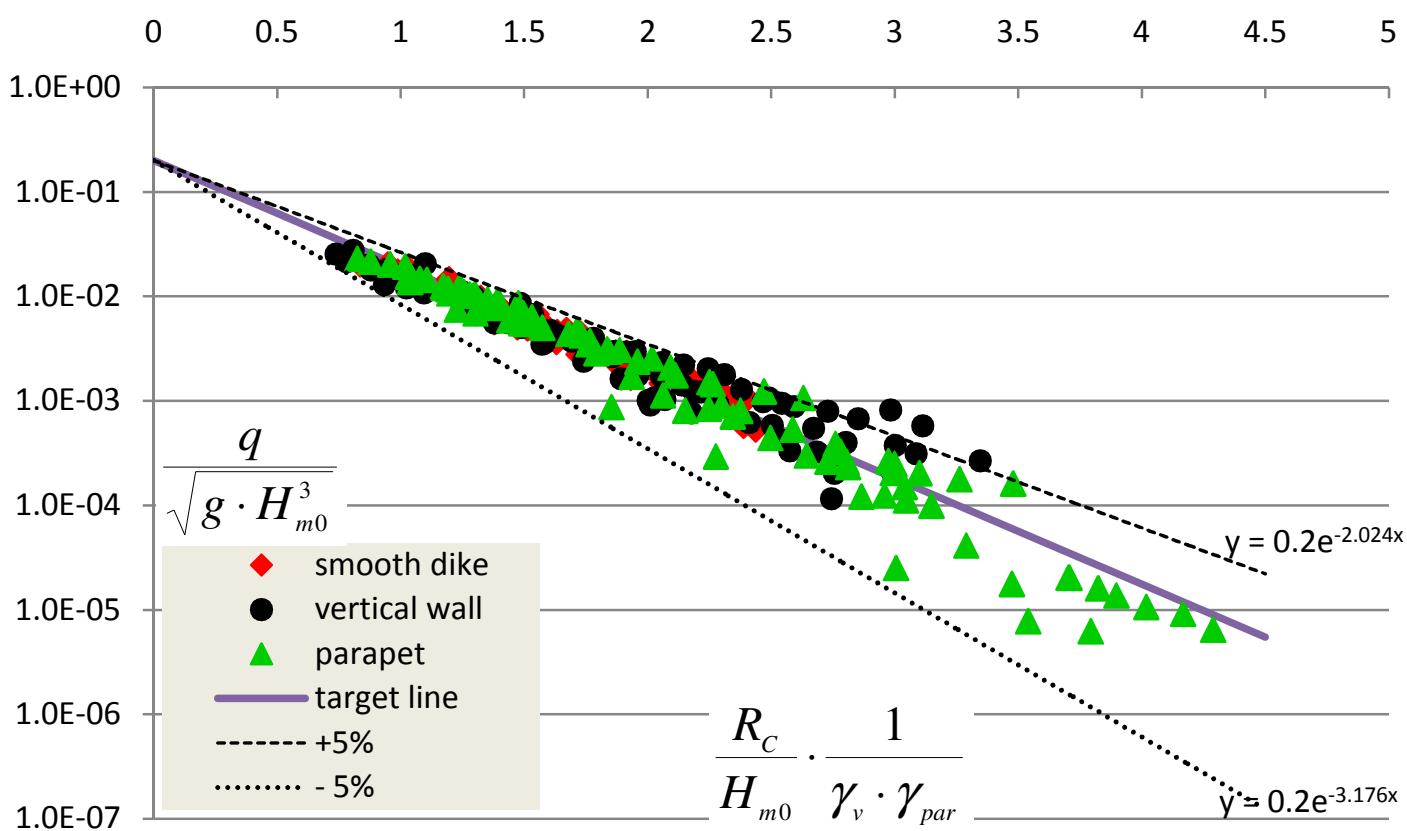

Figure 21. All data plotted in the dimensionless semi logarithmic diagram, where $\gamma_{v}$ and $\gamma_{p a r}$ are included on the abscissa.

When the same data points are now plotted in a log-linear diagram where $\gamma_{\mathrm{v}}$ and $\gamma_{\text {par }}$ are introduced in the abscissa of the graph, the major scatter is reduced significantly. This means all data points for non-breaking waves are much better predicted by the adapted formula

$$
\frac{q}{\sqrt{g \cdot H_{m 0}^{3}}}=0.2 \cdot \exp \left(-2.335 \cdot \frac{R_{C}}{H_{m 0}} \cdot \frac{1}{\gamma_{v} \cdot \gamma_{p a r}}\right)
$$

There still exists some minor scatter around this target line in Figure 21, since a general formula for $\gamma_{\mathrm{v}}$ and $\gamma_{\mathrm{par}}$ has been used instead of the exact calculated $\gamma_{\mathrm{v}}$ and $\gamma_{\mathrm{par}}$ for each individual data point. The good description of the general formulas for $\gamma_{\mathrm{v}}$ and $\gamma_{\mathrm{par}}$ has been made clear in Figure $22\left(\gamma_{\mathrm{v}}\right)$ and Figure $23\left(\gamma_{\text {par }}\right)$.

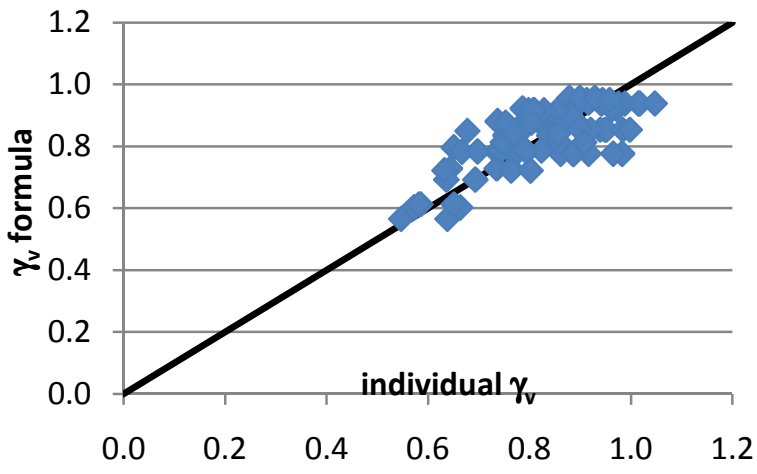

Figure 22. Good correlation between the individual calculated $\gamma_{v}$ for each data point and the prediction of $\gamma_{v}$ by formula (7)

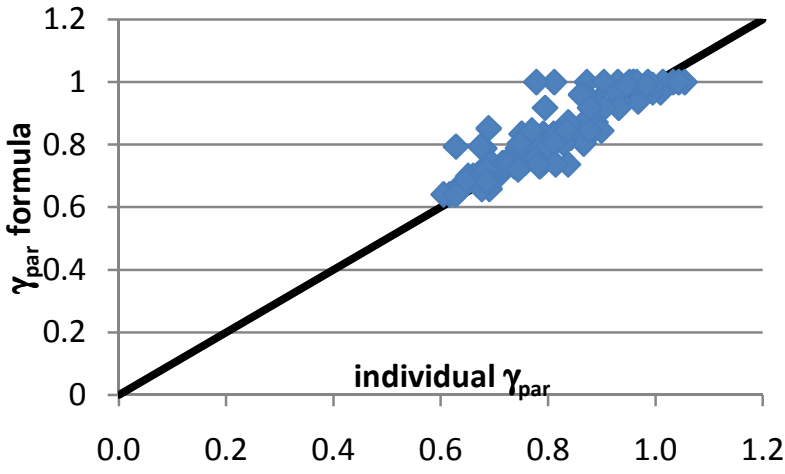

Figure 23. Good correlation between the individual calculated $\gamma_{\text {par }}$ for each data point and the prediction of $\gamma_{\text {par }}$ according to the flowchart

According to Figure 22, a good correlation exists between the formula derived for $\gamma_{v}$ (eq. (7)) and the individual calculated $\gamma_{v}$ 's necessary for 1 data point to shift to the standard equation for a smooth dike $\left(y=0.2 \exp \left(-2.335^{*} \mathrm{x}\right)\right)$. This justifies the use of the formula for $\gamma_{\mathrm{v}}$. But since there exists some scatter in this graph (Figure 22), not all black data points of Figure 20Figure 21 will be moved straight onto the target line by using the $\gamma_{\mathrm{v}}$ formula: some minor scatter amongst the black points in Figure 21 still exists. An analogue conclusion is to be made for $\gamma_{\text {par }}$ in Figure 23 and the green data in Figure 21. 


\section{PRACTICAL GUIDELINES AND CONCLUSIONS}

This research has shown that building a parapet with the same crest height as the original smooth dike can lead to major reduction in wave overtopping. Building this parapet is a rather small modification of new or existing dike structures. For ease of construction and to limit wave impacts on the parapets nose, we advise to design the parapet with a nose angle $\beta \leq 45^{\circ}$. For the height of the nose, a $\lambda$ value of $1 / 3$ is proposed. For that geometry, the minimal value of $\gamma_{\text {par }}$ is nearly reached.

The design storm considered in the Belgian Integrated Coastal Safety Plan has a SWL of TAW + $7 \mathrm{~m}$. Typical dikes in Belgium have a crest height around TAW $+9 \mathrm{~m}$. This leads to a freeboard $\mathrm{R}_{\mathrm{C}}$ of $2 \mathrm{~m}$. When a parapet of $\mathrm{h}_{\mathrm{tot}}=1.2 \mathrm{~m}$ is built in this dike without reducing the crest height, the ratio $h_{\text {wall }} / R_{C}$ becomes 0.6. The upper part of the flowchart can be applied. With $\beta=45^{\circ}$ and $\lambda=1 / 3$, the reduction factors become:

$$
\begin{aligned}
& \gamma_{\mathrm{v}}=0.71 \\
& \gamma_{\beta}=0.58 \\
& \gamma_{\lambda}=0.69 \\
& \gamma_{\mathrm{par}}=0.71 \\
& \gamma_{\mathrm{v}} * \gamma_{\mathrm{par}}=0.51
\end{aligned}
$$

Table 3 gives an example of the average overtopping discharge related to an incoming wave height. Both $\mathrm{q}_{\text {smooth dike, }}, \mathrm{q}_{\text {vertical wall }}$ as $\mathrm{q}_{\text {parapet }}$ are calculated using the above mentioned reduction factors. After each column with the overtopping discharges, the reduction factor related to the reference case smooth dike is shown. Reductions up to 21 times the overtopping discharge can be achieved!

\begin{tabular}{|l|cc|cc|cc|c|}
\hline \multicolumn{1}{|c|}{$\mathrm{H}_{\mathrm{m} 0}[\mathrm{~m}]$} & \multicolumn{2}{|c|}{1.5} & \multicolumn{2}{c|}{2} & \multicolumn{2}{c|}{2.5} & {$[\mathrm{~m}]$} \\
\hline $\begin{array}{c}\text { Overtopping } \\
\text { discharge }\end{array}$ & $\mathrm{q}$ & $\begin{array}{c}\text { reduction } \\
\text { fl/m/s] }\end{array}$ & $\mathrm{q}$ & reduction & $\mathrm{q}$ & reduction & \\
& {$[\mathrm{l} / \mathrm{m} / \mathrm{s}]$} & factor & {$[\mathrm{l} / \mathrm{m} / \mathrm{s}]$} & factor & \\
\hline q (smooth dike) & $\mathbf{5 1 . 1 6}$ & - & $\mathbf{1 7 1 . 5 3}$ & - & $\mathbf{3 8 2 . 4 0}$ & - & {$[\mathrm{l} / \mathrm{s} / \mathrm{m}]$} \\
q (vertical wall) & 14.37 & 3.6 & $\mathbf{6 6 . 2 0}$ & 2.6 & $\mathbf{1 7 8 . 5 3}$ & 2.17 & {$[\mathrm{l} / \mathrm{s} / \mathrm{m}]$} \\
q (parapet) & $\mathbf{2 . 4 8}$ & 20.7 & $\mathbf{1 7 . 7 1}$ & 9.7 & $\mathbf{6 2 . 1 8}$ & 6.2 & {$[\mathrm{l} / \mathrm{s} / \mathrm{m}]$} \\
\hline
\end{tabular}

Table 3. Overtopping discharges and related reduction factors compared to the smooth dike.

\section{FUTURE RESEARCH}

Wave forces on the parapet and individual wave overtopping volumes will be studied in the future.

\section{ACKNOWLEDGEMENTS}

The authors of this paper would like to acknowledge the work of the technical staff of the Department of Civil Engineering (Coastal Division) of Ghent University. Also the help and insight of Gilles Vanhouwe and Tobias Boderé was useful during this study.

\section{REFERENCES}

Boderé T., Vanhouwe G. (2010), Reduction of Wave overtopping at Smooth Dikes: Combination of Berm and Vertical Wall. (in Dutch) Master Thesis 2010, Ghent University.

Den Heijer F. (1998), "Wave overtopping and forces on vertical structures" (in Dutch). WL Delft Hydraulics, report $\mathrm{nr} \mathrm{H} 2014$

EurOtop 2007. Wave Overtopping of Sea Defences and Related Structures: Assessment Manual. www.overtopping-manual.com

Franco L., de Gerloni M., van der Meer J.W. (1994), "Wave overtopping on vertical and composite breakwaters". Proceedings of 24th International Conference on Coastal Engineering, ICCE 1994, ASCE, 1030-1044.

Goda Y. (1985), "Random seas and design of maritime structures." University of Tokyo Press.

Mansard, E. P. D. and Funke E. R. (1980). The measurement of incident and reflected spectra using a least squares method. Proceedings of 17th International Conference on Coastal Engineering, ICCE 1980, ASCE, 154-172.

TAW 2002. Technical report. Wave runup and wave overtopping at dikes. (in Dutch), TAW Technical Advisory committee on Flood Defences. J.W. van der Meer 